\title{
Endothelin's Biphasic Effect on Fluid Absorption in the Proximal Straight Tubule and Its Inhibitory Cascade
}

\author{
Nestor H. Garcia and Jeffrey L. Garvin \\ Division of Hypertension and Vascular Research, Henry Ford Hospital, Detroit, Michigan 48202
}

\begin{abstract}
The effect of endothelin-1 (ET-1) on the proximal tubule remains unclear. This may be due to a biphasic effect on transport in this segment. We hypothesized that ET-1 has a biphasic effect on fluid absorption ( $\mathrm{Jv}$ ) in the proximal straight tubule and that its inhibitory effect is superimposed on its stimulatory effect. ET-1 $\left(10^{-13} \mathrm{M}\right)$ stimulated $\mathrm{Jv}$ from $0.68 \pm 0.07$ to $1.11 \pm 0.20 \mathrm{nl} / \mathrm{mm} / \mathrm{min}$, a $60 \%$ increase $(P<0.04) .10^{-12}$ and $10^{-10} \mathrm{M}$ ET-1 had no significant effect. $10^{-9} \mathrm{M}$ ET-1 reduced Jv from $0.81 \pm 0.19$ to $0.44 \pm 0.15 \mathrm{nl} / \mathrm{mm} / \mathrm{min}(P<0.009)$. Staurosporine (STP, $10^{-8} \mathrm{M}$ ) prevented both $10^{-9}$ and $10^{-13}$ M ET-1 from altering $\mathrm{Jv}$ significantly indicating that protein kinase $\mathrm{C}(\mathrm{PKC})$ is involved. Indomethacin $\left(10^{-5} \mathrm{M}\right)$ blocked the inhibition produced by $10^{-9} \mathrm{M}$ ET-1. ETI $\left(10^{-6} \mathrm{M}\right)$, a lipoxygenase inhibitor, also blocked ET-1 inhibition of Jv. Interestingly ET-1 $\left(10^{-9} \mathrm{M}\right)$ stimulated $\mathrm{Jv}$ in the presence of both indomethacin and ETI. When $10^{-9} \mathrm{M}$ ET-1 was added in the presence of $10^{-5} \mathrm{M}$ quinacrine, a phospholipase ( $\left.P L\right)$ inhibitor, $\mathrm{Jv}$ also increased from $1.02 \pm 0.20$ to $1.23 \pm 0.22 \mathrm{nl} / \mathrm{mm} /$ $\min (P<0.03)$. STP blocked this increase. We conclude that (a) $10^{-13} \mathrm{M}$ ET-1 stimulates fluid absorption by activating PKC; (b) $10^{-9}$ M ET-1 decreases Jv by PKC-, PL-, cyclooxygenase-, and lipoxygenase-dependent mechanisms; and $(c)$ the inhibitory effect of ET-1 on Jv is superimposed on the stimulatory effect. (J. Clin. Invest. 1994. 93:2572-2577.) Key words: transport • protein kinase $\mathrm{C} \cdot$ phospholipase $\bullet$ prostaglandin • leukotrienes
\end{abstract}

\section{Introduction}

While the vasoconstrictor endothelin (ET-1 $)^{1}$ has been extensively studied in a variety of tissues $(1,2,3)$, its action and second messenger pathway in the proximal tubule are not entirely clear. ET-1 has been reported to be both antinatriuretic

Results of this experiment were presented in part at the 25th Annual Meeting of the American Society of Nephrology (Baltimore, MD, November 15-17, 1992) and at the 10th Meeting of the Inter-American Society of Hypertension (La Jolla, CA, April 25-29, 1993).

Address correspondence to J. L. Garvin, Ph.D., Division of Hypertension and Vascular Research, Henry Ford Hospital, 2799 W. Grand Blvd., Detroit, MI 48202.

Received for publication 21 June 1993 and in revised form 24 December 1993.

1. Abbreviations used in this paper: ET-1, endothelin; INDO, indomethacin; Jv, fluid absorption; LT, leukotrienes; PKC, protein kinase C; PL, phospholipase; PST, proximal straight tubule; QNC, quinacrine; STP, staurosporine.

J. Clin. Invest.

(c) The American Society for Clinical Investigation, Inc.

$0021-9738 / 94 / 06 / 2572 / 06 \$ 2.00$

Volume 93, June 1994, 2572-2577
(4) and natriuretic $(5,6)$. The antinatriuresis may have been due to decreases in glomerular filtration and renal blood flow whereas the natriuretic effect was independent of its action on renal hemodynamics indicating that endothelin acts directly on the nephron. There is in vivo evidence for both proximal and distal nephron effects. Perico et al. (5) reported that this effect is only on the proximal tubule; while other in vivo data indicate that ET-1 induces natriuresis and diuresis to direct action of the peptide in both the proximal and distal nephron (6).

In addition to the in vivo data there is in vitro data concerning an effect of ET-1 on the proximal nephron. Garvin and Sanders (7) using isolated, perfused rat proximal straight tubules (PST) reported that $10^{-9} \mathrm{M}$ ET-1 inhibited fluid absorption $(\mathrm{Jv})$, consistent with the natriuretic effects reported by Perico et al. (5) and Harris et al. (6). In contrast, Eiam-Ong et al. (1) reported only increased $\mathrm{Na}^{+}$transport with $10^{-8}$ to $10^{-11}$ M ET-1 using basolateral and brush border membrane vesicles. This effect was dependent on activation of $\mathrm{Na}^{+} / \mathrm{H}^{+}$ exchange and $\mathrm{Na}^{+} / \mathrm{HCO}_{3}^{-}$cotransport. Additionally, Guntupalli et al. (8), using brush border membrane vesicles, found that $10^{-9}$ to $10^{-11} \mathrm{M} \mathrm{ET}-1$ increased $\mathrm{Na}^{+} /$phosphate and $\mathrm{Na}^{+} /$ $\mathrm{H}^{+}$transport while $10^{-7}$ M ET-1 inhibited them. Finally, Zeidel et al. (9) reported that oxygen consumption in the proximal convoluted tubule, and consequently sodium transport, was not affected by ET-1. The disparate results may be due to the biphasic effect of endothelin.

In light of the ambiguity regarding the effect of endothelin on transport, it is not surprising that data concerning the second messenger cascade are also conflicting. Guntupalli et al. (8) concluded that both the inhibition and stimulation of transport induced by ET-1 are due to the participation of phospholipase (PL) $C$ and protein kinase $C$ (PKC). In contrast, Perico et al. (5) showed that oral administration of a specific 5-lipoxygenase inhibitor (L-651,392) in rats prevented the increased urine flow rate and absolute and fractional sodium excretion caused by a single i.v. bolus of $0.3 \mathrm{ml}$ of ET-1 administered over $1 \mathrm{~min}$ in a dose of $150 \mathrm{pmol}$ ET-1.

The purpose of this work was $(a)$ to investigate whether ET-1 has a biphasic effect on transport in isolated proximal straight tubule; and $(b)$ to study the second messenger cascade whereby it affects $\mathrm{Jv}$ in the proximal tubule. We found that $(a)$ $10^{-13} \mathrm{M}$ ET-1 stimulates fluid absorption by activating PKC; (b) $10^{-9}$ M ET-1 decreases Jv by PKC-, PL-, cyclooxygenase-, and lipoxygenase-dependent mechanisms; and $(c)$ the inhibitory effect of ET-1 on Jv is superimposed on the stimulatory effect.

\section{Methods}

Male Sprague-Dawley rats weighing 120-180 g (Charles River Breeding Laboratories, Inc. Wilmington, MA) were maintained on a diet containing $0.22 \%$ sodium and $1.1 \%$ potassium (Ralston Purina, Rich- 
mond, IN) for at least $5 \mathrm{~d}$. Rats were anesthetized with ketamine $(0.1$ $\mathrm{mg} / \mathrm{kg}$; Parke-Davis, Morris Plains, NJ). The peritoneal cavity was opened and flushed with cold $150 \mathrm{mM} \mathrm{NaCl}$. The left kidney was excised and placed in cold dissection medium equilibrated with $95 \% \mathrm{O}_{2}-$ $5 \% \mathrm{CO}_{2}$ while still perfused with blood. After removal, the left kidney was placed in chilled saline. Coronal slices were transferred to a dissection dish containing physiological saline at $12^{\circ} \mathrm{C}$. Medullary rays were dissected from the slices, and proximal straight tubules were dissected from the rays. Cortical segments were transferred to a perfusion chamber, mounted on concentric pipets $(10)$, and perfused at $37^{\circ} \mathrm{C}$.

The composition of the perfusion solution (in $\mathrm{mM}$ ) was: $\mathrm{NaCl}$, $114.0 ; \mathrm{KCl}, 4.0 ; \mathrm{NaH}_{2} \mathrm{PO}_{4}, 2.5 ; \mathrm{MgSO}_{4}, 1.2 ; \mathrm{Na}$ citrate, $1.0 ; \mathrm{NaHCO}_{3}$, 25.0; alanine, 6.0; Ca lactate ${ }_{2}, 2.0$ : glucose, 5.5; and raffinose, 5.0. The perfusion and bath solutions were generally the same, except that the latter had ET-1 and/or inhibitors added. The osmolarity of all solutions was $295 \pm 3 \mathrm{mOsm}$ as measured by freezing-point depression. The $\mathrm{pH}$ of the bath was 7.4. Solutions were gassed with $95 \% \mathrm{O}_{2}-5 \% \mathrm{CO}_{2}$. When ET-1 and drugs were added to the bath, 20 min elapsed before measurements were made. ET-1 was purchased from Peninsula Laboratories Inc. (Belmont, CA ), indomethacin from Merck Sharp \& Dohme Research Laboratories (West Point, PA), staurosporine from Boehringer Mannheim (Indianapolis, IN), quinacrine from Sigma Chemical Co. (St. Louis, MO), ETI ( 5,8,11-eicosatriynoic acid) from Calbiochem-Novabiochem Corp. (La Jolla, CA), and L-660,771 a potent and selective leukotriene $D_{4}$ receptor antagonist (11) was a gift from Dr. A. W. Ford-Hutchinson (Merck Frosst Canada, Pointe Claire-Dorval, Quebec, Canada).

Fluid absorption ( Jv) was measured using raffinose as a volume marker. Raffinose was measured in the perfusate and collected fluid using a previously described enzymatic assay with a continuous-flow ultramicrofluorometer (12). The perfusion rate (Vo) was calculated from the equation

$\mathrm{Vo}_{\mathrm{o}}=(\mathrm{CL} / \mathrm{Co}) \mathrm{VL}$

where $\mathrm{CL}$ is the concentration of raffinose in the collected fluid, $\mathrm{Co}$ is the concentration of raffinose in the perfused fluid, and VL is the collection rate per unit of tubule length. The rate of $\mathrm{Jv}$ was calculated from the equation

$\mathrm{Jv}=\mathrm{Vo}-\mathrm{VL}$

Statistics. Values are reported as mean \pm standard error. Student's paired $t$ test was used to test for significant differences. One-tailed test was used in protocols involving indomethacin $\left(10^{-4} \mathrm{M}\right)$ and in ETI $\left(10^{-6} \mathrm{M}\right)$ plus indomethacin $\left(10^{-5} \mathrm{M}\right)$. Two-tailed tests were performed in the rest of the protocols. All experiments in which at least two measurements of $\mathrm{Jv}$ were made during each period were reported.

\section{Results}

To investigate whether ET-1 has a biphasic effect on Jv, intact isolated rat PSTs were incubated with different concentrations of ET-1 in the basolateral bath and Jv was measured. The effect of each concentration of ET-1 was examined in separate studies (Fig. 1). When six PSTs were perfused at a rate of $4.89 \pm 0.34 \mathrm{nl} / \mathrm{min} / \mathrm{mm}$; Jv was $0.68 \pm 0.07 \mathrm{nl} / \mathrm{min} / \mathrm{mm}$. After we treated the tubules with $10^{-13} \mathrm{M}$ ET-1, Jv rose to $1.11 \pm 0.20$ $\mathrm{nl} / \mathrm{min} / \mathrm{mm}$, an increase of $60 \%(P<0.04)$. Next we tested $10^{-12} \mathrm{M} \mathrm{ET}-1$. During the control period Jv in four tubules was $1.09 \pm 0.27 \mathrm{nl} / \mathrm{min} / \mathrm{mm}$. Jv was $1.22 \pm 0.32 \mathrm{nl} / \mathrm{min} / \mathrm{mm}$ after ET-1 was added to the bath, a small and insignificant increase. $10^{-10}$ M ET-1 decreased Jv slightly. Finally, we examined the effect of $10^{-9} \mathrm{M} \mathrm{ET}-1$ on Jv (Fig. 1). Five PSTs were perfused at a rate of $5.69 \pm 0.35 \mathrm{nl} / \mathrm{min} / \mathrm{mm}$; Jv was $0.81 \pm 0.19 \mathrm{nl} / \mathrm{min} /$ $\mathrm{mm}$. After ET- $1\left(10^{-9} \mathrm{M}\right)$ was added to the bath, Jv decreased to $0.44 \pm 0.15 \mathrm{nl} / \mathrm{min} / \mathrm{mm}(P<0.01)$. Time controls showed no significant change in $\mathrm{Jv}(P>0.80)$. We concluded that

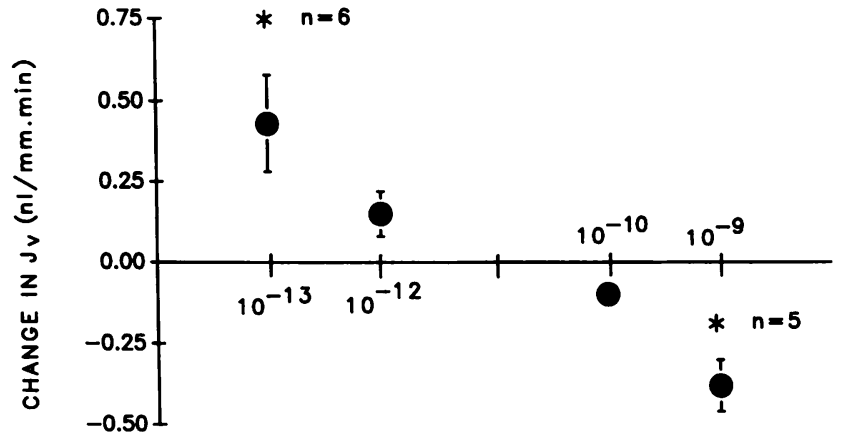

ENDOTHELIN CONCENTRATION (M)

Figure 1. Effect of varying doses of ET-1 on fluid absorption by rat proximal straight tubules. $10^{-13} \mathrm{M} \mathrm{ET}-1$ increased $\mathrm{Jv}$ by $60 \%$ (from $0.68 \pm 0.07$ to $1.11 \pm 0.20 ; P<0.04 ; n=6) .10^{-9}$ M ET-1 decreased $\mathrm{Jv}$ from $0.81 \pm 0.19$ to $0.44 \pm 0.15(P<0.01 ; n=5)$.

ET-1 has a biphasic effect on fluid absorption in intact isolated rat proximal tubules.

PKC has been implicated as a mediator of ET-1's effect in several tissues $(2,3,13)$ and a mediator of $\mathrm{Na}^{+} / \mathrm{H}^{+}$exchange activity in proximal tubule cells $(8,14,15,16)$. Since both stimulation and inhibition of $\mathrm{Na}^{+} / \mathrm{H}^{+}$exchange by ET-1 is reportedly dependent on activation of PKC (8), we tested whether suppression of PKC would influence both effects of ET-1 on Jv. The PKC inhibitor staurosporine (STP; $10^{-8} \mathrm{M}$ ) was added to the bath at the beginning of the incubation period and maintained for the duration of the experiment. First we examined the ability of $10^{-13} \mathrm{M}$ ET-1 to stimulate $\mathrm{Jv}$ in the presence of STP. Six PSTs were perfused in the presence of $10^{-8} \mathrm{M}$ STP. When $10^{-13} \mathrm{M}$ ET- 1 was added to the bath, Jv did not change significantly (from $0.77 \pm 0.08$ to $0.66 \pm 0.14 \mathrm{nl} /$ $\mathrm{min} / \mathrm{mm})(P>0.40)$. Next we tested $10^{-9} \mathrm{M}$ ET-1. During the control period, five PSTs were perfused at a rate of 5.46 \pm 0.47 $\mathrm{nl} / \mathrm{min} / \mathrm{mm}$ in the presence of STP; Jv was $0.65 \pm 0.08 \mathrm{nl} / \mathrm{min} /$ $\mathrm{mm}$. After we added $10^{-9} \mathrm{M}$ ET-1 to the bath, Jv was $0.63 \pm 0.05 \mathrm{nl} / \mathrm{min} / \mathrm{mm}(P>0.80)$ (Fig. 2). STP alone did not change Jv significantly. Time controls with STP present from the start showed no change in Jv. These data indicate that both the stimulatory and inhibitory effects of ET-1 are dependent on activation of PKC.

Since the increase in Jv induced by ET-1 is readily explained by PKC directly stimulating $\mathrm{Na}^{+} / \mathrm{H}^{+}$exchange activity $(14,15)$, we did not pursue the mechanism of the stimula-

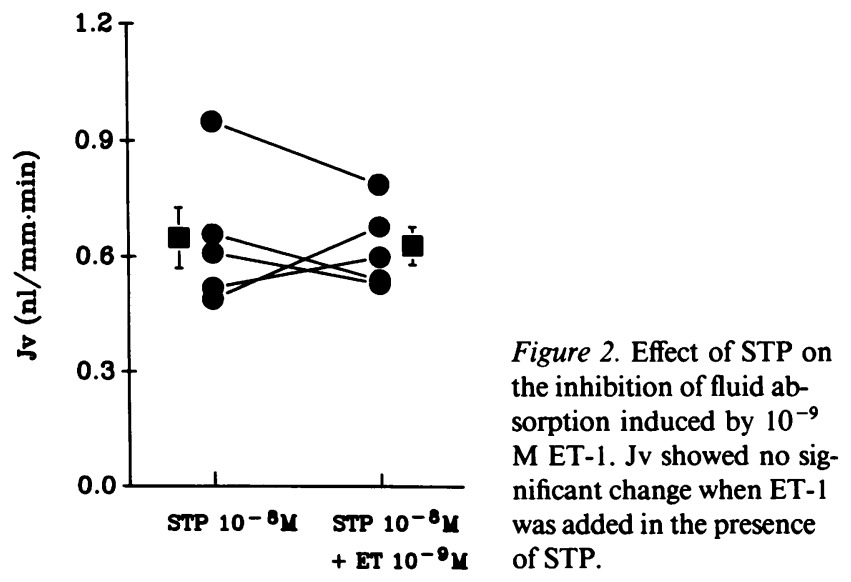


tion further. The mechanism whereby ET-1 could inhibit Jv by activating PKC is less clear. However, PKC can activate phospholipase $A_{2}$ and $D(17)$, and in this way could stimulate prostaglandin synthesis. Prostaglandins have been shown to inhibit fluid absorption in the proximal nephron (18) and ET-1-induced inhibition of $\mathrm{Na}^{+}$transport in the collecting duct is due to prostaglandin release (9). Consequently, we investigated whether prostaglandins mediate the inhibitory effect of $10^{-9} \mathrm{M}$ ET-1 using the cyclooxygenase inhibitor, indomethacin (INDO, $10^{-5} \mathrm{M}$ ). INDO was added to the bath at the beginning of the incubation period and maintained for the remainder of the experiment. During the control period, eight proximal tubules were perfused at a rate of $3.98 \pm 0.53 \mathrm{nl} / \mathrm{min} /$ $\mathrm{mm}$ in the presence of INDO; Jv was $0.62 \pm 0.16 \mathrm{nl} / \mathrm{min} / \mathrm{mm}$. When we added $10^{-9} \mathrm{M}$ ET to the bath, Jv did not change significantly $(P>0.90)$ (Fig. 3$)$. INDO alone did not change Jv significantly from the control value $(P>0.70)$. Time controls with INDO present from the start showed no significant change in $\mathrm{Jv}(P>0.70)$. From these data we concluded that cyclooxygenase products mediate ET-1's inhibition of $\mathrm{Jv}$ in the PST.

It is well known that arachidonic acid, the precursor of prostaglandins (PG) and leukotrienes, can be released by phospholipase (PL) $\mathrm{A}_{2}$ or $\mathrm{D}$. To add further evidence that arachidonic acid is involved in the decrease in Jv caused by ET-1, we tested whether inhibition of PL $A_{2}$ and $D$ would block this effect. The PL D and $A_{2}$ inhibitor quinacrine ( $Q N C, 10^{-5} \mathrm{M}$ ) was added to the bath at the beginning of the incubation period and maintained for the duration of the experiment. During the control period, eight tubules were perfused at a rate of $4.54 \pm 0.58 \mathrm{nl} / \mathrm{min} / \mathrm{mm}$ in the presence of QNC; Jv was $1.02 \pm 0.20 \mathrm{nl} / \mathrm{min} / \mathrm{mm}$. When we added $10^{-9} \mathrm{M}$ ET- 1 to the bath, Jv surprisingly increased from $1.02 \pm 0.20$ to $1.23 \pm 0.22$ $\mathrm{nl} / \mathrm{min} / \mathrm{mm}(P<0.03)$ (Fig. 4). QNC alone did not significantly affect Jv. Time controls with QNC present from the start showed no change in Jv. Thus blockade of PL D and/or $A_{2}$ revealed a stimulatory effect of $10^{-9} \mathrm{M}$ ET-1 on Jv.

To examine the possibility that stimulation of $\mathrm{Jv}$ by $10^{-9} \mathrm{M}$ ET-1 in QNC-treated PSTs was due to the same mechanism as activated by $10^{-13} \mathrm{M}$ (i.e., activation of PKC), we incubated tubules in the presence of STP and QNC. Jv was $0.79 \pm 0.20$ $\mathrm{nl} / \mathrm{min} / \mathrm{mm}$ during the control period with both inhibitors and $0.70 \pm 0.15 \mathrm{nl} / \mathrm{mm} / \mathrm{min}$ after $10^{-9} \mathrm{M}$ ET- 1 was added to the bath, a value not significantly different from control $(P>0.40)$ (Fig. 5). From these data we concluded that the stimulation of

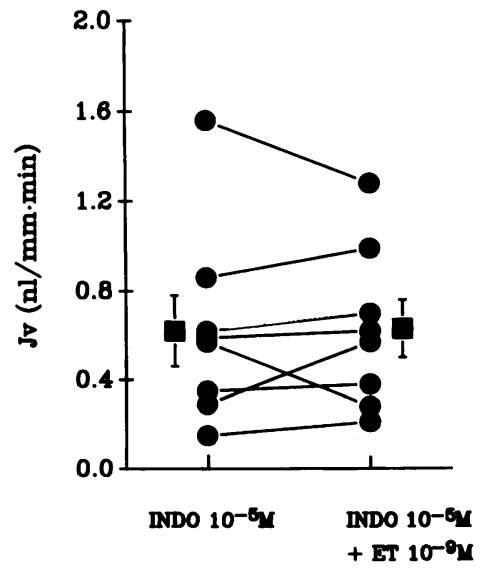

Figure 3. Effect of INDO on the inhibition of fluid absorption induced by $10^{-9}$ M ET-1. INDO $\left(10^{-5} \mathrm{M}\right)$ was added to the bath and $\mathrm{Jv}$ measured before and after addition of $10^{-9} \mathrm{M}$ ET-1. Jv showed no signifcant change when ET-1 was added in the presence of INDO.

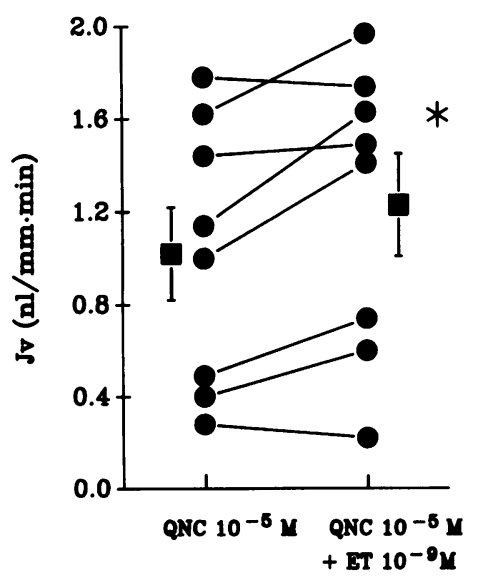

Figure 4. Effect of QNC on the inhibition of fluid absorption induced by $10^{-9}$ M ET-1. Jv showed no significant decrease when ET1 was added in the presence of $10^{-5} \mathrm{M}$ QNC (from $1.02 \pm 0.20$ to $1.23 \pm 0.22 ; P$ $<0.03 ; n=8$ ). Time controls showed no significant changes.

Jv by $10^{-9} \mathrm{M} \mathrm{ET}-1$ in QNC-treated tubules is due to activation of PKC.

Since $10^{-9} \mathrm{M}$ endothelin increased fluid absorption in QNC-treated tubules but not in tubules treated with $10^{-5} \mathrm{M}$ indomethacin, we hypothesized that the inability of $10^{-9} \mathrm{M}$ endothelin to stimulate fluid absorption in the presence of $10^{-5}$ $M$ indomethacin was due to incomplete inhibition of cyclooxygenase. To test this hypothesis we examined the effect of $10^{-9}$ $M$ endothelin on fluid absorption by tubules which had been pretreated with $10^{-4} \mathrm{M}$ indomethacin. In the presence of $10^{-4}$ $M$ indomethacin $\mathrm{Jv}$ was $0.77 \pm 0.10 \mathrm{nl} / \mathrm{min} / \mathrm{mm}$, and when endothelin $10^{-9} \mathrm{M}$ was added to the bath Jv increased $\sim 20 \%$ $(n=4, P<0.05)$. This increase was similar to that seen in the presence of quinacrine.

Because Perico et al. (5) reported that the natriuresis induced by ET-1 is mediated by leukotrienes (LT), and it is possible that at a concentration of $10^{-4} \mathrm{M}$ indomethacin could be inhibiting enzymes besides cyclooxygenase, we investigated the ability of a selective LT $D_{4}$ receptor antagonist, L-660,711 (11), to block the effect of $10^{-9} \mathrm{M}$ ET-1. When we perfused PSTs in the presence of L-660,711 and Jv was $0.63 \pm 0.06 \mathrm{nl} /$ $\mathrm{min} / \mathrm{mm}$. When ET-1 $10^{-9} \mathrm{M}$ was added, Jv decreased from $0.63 \pm 0.06 \mathrm{nl} / \mathrm{min} / \mathrm{mm}$ to $0.31 \pm 0.06 \mathrm{nl} / \mathrm{min} / \mathrm{mm}(P<0.02)$. This decrease was similar to that found in the absence of the leukotriene receptor antagonist.

Next we blocked the synthesis of leukotrienes with a lipoxygenase inhibitor, ETI $\left(10^{-6} \mathrm{M}\right)$. ETI was added to the bath at the beginning of the incubation period and maintained for the

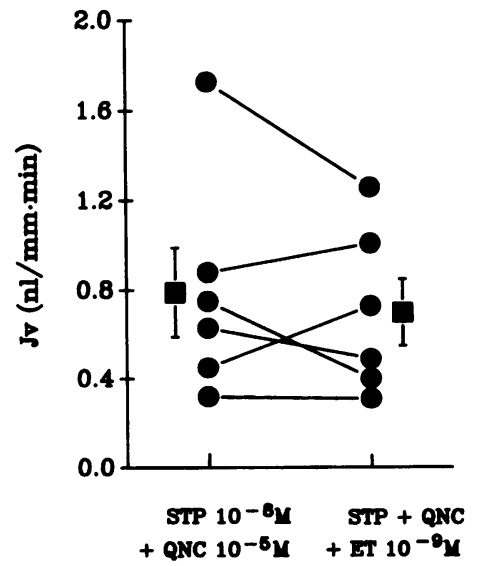

Figure 5. Effect of STP and QNC on the inhibition of fluid absorption induced by $10^{-9}$ M ET-1. Jv showed no significant change when ET-1 was added in the presence of both inhibitors. 
remainder of the experiment. During the control period, PSTs were perfused at a rate of $3.16 \pm 0.35 \mathrm{nl} / \mathrm{min} / \mathrm{mm}$ in the presence of ETI; Jv was $0.73 \pm 0.15 \mathrm{nl} / \mathrm{min} / \mathrm{mm}$. When we added $10^{-9} \mathrm{M}$ ET to the bath, Jv did not change significantly ( $P$ $>0.60$ ). ETI alone did not change Jv significantly from the control value $(P>0.60)$. From these data we concluded that the inhibition induced by ET-1 is mediated, in part, by lipoxygenase products.

To examine if the stimulatory effect induced by ET-1 $10^{-9}$ $M$ in QNC-treated tubule was due to the blockade of PG and LT production, we incubated proximal straight tubules in the presence of both inhibitors, INDO $\left(10^{-5} \mathrm{M}\right)$ and ETI $\left(10^{-6}\right.$ $M)$. In the presence of both inhibitors when $10^{-9} \mathrm{M} \mathrm{ET}-1$ was added, $\mathrm{Jv}$ increased by $16.5 \%(P<0.05)$. Indomethacin and ETI together did not change fluid absorption from the control value $(P>0.70)$. From these data we concluded that both cyclooxygenase and lipoxygenase products are responsible for the inhibitory effects of $10^{-9} \mathrm{M}$ ET-1. When both pathways are blocked, a stimulatory effect is revealed.

\section{Discussion}

The effects of endothelin on the proximal tubule and the second messenger system(s) involved are unclear. We found that ET-1 had a biphasic effect on Jv. The stimulatory effect was mediated by activation of PKC. Interestingly, the inhibitory effect was also mediated by activation of PKC and dependent on PL, cyclooxygenase, and lipoxygenase activity.

Since Yanagisawa et al. (19) reported the vascular effect of endothelin, there have been several investigations into its renal actions. Intravenous infusion of endothelin $(50 \mathrm{ng} / \mathrm{kg} / \mathrm{min})$ in dogs has been reported to be antinatriuretic (4); however, this antinatriuretic effect was due to a marked reduction in both renal blood flow and glomerular filtration rate. A single i.v. bolus of 75-150 pmol of ET-1 administered over $1 \mathrm{~min}$ to rats caused diuretic and natriuretic effects that were independent of its action on renal hemodynamics (5). These effects were dependent on a direct action in the proximal tubule as determined by lithium clearance. Other in vivo data indicate that infusion of 1 and $10 \mathrm{ng} / \mathrm{kg} / \mathrm{min}$ endothelin induces natriuresis and diuresis in anesthetized rats (6). Endothelin significantly increased both fractional sodium excretion and lithium clearance. The increase in lithium clearance only partially accounted for the increase in fractional sodium excretion, indicating that the natriuresis was due in part to direct action of the peptide on the proximal tubule and in part to other segments. In an attempt to clarify this issue, assess the role of the proximal nephron in this response, and address the issue of the second messenger(s) involved, we examined the effects of different concentrations of ET-1 on fluid absorption in the isolated, perfused rat proximal straight tubule.

In this study ET-1 had a biphasic effect on fluid absorption in isolated, perfused rat proximal straight tubules. ET-1 increased fluid absorption by $60 \%$ at a concentration of $10^{-13} \mathrm{M}$, while at $10^{-12} \mathrm{M}$ stimulation was less marked. ET-1 had no effect on fluid absorption at $10^{-10} \mathrm{M}$ and actually inhibited it by $50 \%$ at $10^{-9} \mathrm{M}$. The inhibitory effect of ET-1 on fluid absorption is consistent with previously published data from our laboratory which showed that $10^{-9} \mathrm{M}$ ET-1 decreased fluid absorption in the proximal tubule also by $50 \%$ (7).

The biphasic effect of endothelin is not unique to this hor- mone or preparation. A similar biphasic effect has been reported for the response of the proximal nephron to angiotensin II $(20,21)$. Endothelin has also been reported to have a biphasic effect on cultured lactotrophs (22). A similar effect was demonstrated in rat brush border membrane vesicles, although the dose-response curve was shifted toward higher concentrations. $10^{-9}$ to $10^{-11} \mathrm{M}$ ET-1 increased $\mathrm{Na}^{+} /$phosphate transport by $52 \%$ and $\mathrm{Na}^{+} / \mathrm{H}^{+}$exchange activity by $81 \%$, whereas $10^{-7} \mathrm{M}$ decreased the activity of both transporters (8). The apparent difference in the dose-response relationship between isolated, perfused proximal tubules and brush border membrane vesicles may be due to the fact that in our study ET-1 was added to the basolateral bath as opposed to being exposed to the luminal membrane. This difference in protocols raises the possibility that either the receptors on the luminal and basolateral membranes differ or that in the study using brush border membrane vesicles the actual endothelin concentration was lower than that reported due to the presence of proteases in the luminal membrane. The proximal nephron brush border membrane is rich in proteases (23), and breakdown of endothelin by such enzymes has been documented $(24,25)$. The use of proteinase inhibitors in brush border membrane vesicle experiments could address this issue.

In contrast to the biphasic effect of endothelin on transport noted above, Eiam-Ong et al. (1), using brush border membrane vesicles from rabbits, described only a stimulatory effect of $10^{-8}$ to $10^{-11} \mathrm{M}$ ET-1. Their inability to demonstrate a biphasic effect may be due to either the presence of proteases as described above or a true species difference.

Although several investigators have reported an effect of ET-1 on transport processes in proximal tubule preparations, there have also been several reports which seem to indicate that ET-1 does not affect the proximal nephron $(9,26,27)$. While the cause of this is not absolutely certain, there are likely explanations for the discrepancy. The report that there was little or no specific ${ }^{125}$ I endothelin binding data may have been due to insufficient specific activity of the endothelin, which could detect the large number of receptors in the inner medullary collecting duct, but not in all segments of the proximal nephron. Low but significant binding was found in S1 (27). The inability of Terada et al. (26) to find ET-1 receptor mRNA is likely due to the low number of mRNAs for membrane-bound receptors or use of tissue in which the message was degraded. Finally, the report that ET-1 does not affect oxygen consumption may simply have been due to use of a dose that does not affect transport greatly, i.e., $10^{-12}$ through $10^{-10} \mathrm{M}(9)$. What ever the explanation for the negative results, they in no way alter the importance of the findings of this paper or those which show that ET-1 can effect proximal nephron transport. Physiologically, the effect of ET-1 on the proximal nephron may be of great significance, since the proximal nephron absorbs $60-70 \%$ of the filtered sodium while the collecting duct only absorbs $\sim 6 \%$.

The stimulation of Jv induced by $10^{-13} \mathrm{M}$ ET-1 was inhibited by staurosporine, indicating that it involved the activation of PKC. The participation of PKC in endothelin's effect has been described for other tissues such as smooth muscle (28) using different inhibitors or downregulation of protein kinase C (2). ET-1s role in PKC activation was also described in rat brush border membrane vesicles, where staurosporine inhibited the endothelin-induced stimulation of both $\mathrm{Na}^{+} / \mathrm{H}^{+}$and $\mathrm{Na}^{+} /$phosphate transporters (8). Analogously, PKC has been 
shown to be part of the second messenger cascade whereby angiotensin II stimulates fluid absorption in the proximal nephron (19). Simonson et al. (13) reported that $10^{-13} \mathrm{M}$ ET-1 stimulated phospholipase $C$ activity and increased intracellular calcium levels and presumably PKC in cultured rat messangial cells. This effect was followed by activation of $\mathrm{Na}^{+} /$ $\mathrm{H}^{+}$exchange as measured by alkalinization of intracellular $\mathrm{pH}(16)$.

Interestingly, we also found that the inhibitory effect of endothelin was blocked by staurosporine, indicating that activation of PKC is also involved in the endothelin-induced inhibition of fluid absorption. PKC has been described as an inhibitor of $\mathrm{Na}^{+} / \mathrm{K}^{+}$ATPase activity in the proximal tubule as part of the signaling system used by dopamine (29); however, it is not clear whether PKC was acting directly or through some other enzyme(s). It is unlikely that PKC was acting directly to inhibit $\mathrm{Na}^{+} / \mathrm{K}^{+}$ATPase in our experiments, since the inhibition could be blocked by quinacrine, indomethacin and ETI; steps subsequent to activation of PKC. PKC activation in the endothelin-induced inhibition of both $\mathrm{Na}^{+} / \mathrm{H}^{+}$and $\mathrm{Na}^{+} /$phosphate transporters (8) was also described in rat brush border membrane vesicles where there is no $\mathrm{Na}^{+} / \mathrm{K}^{+}$ATPase.

In this study we found that the inhibition of fluid absorption induced by endothelin could be blocked by inhibiting either phospholipase $\mathrm{A}_{2}$ and / or D, cyclooxygenase or lipoxygenase. These experiments indicate that release of arachidonic acid is vital to ET-1's inhibitory effect. Additionally, we show that subsequent production of prostaglandins and leukotrienes by the fore-mentioned enzymes can account for the inhibitory effect. A role for prostaglandin in the inhibition is not surprising. Prostaglandins have been shown to inhibit transport in the proximal nephron (18), MDCK cells (30), and the cortical collecting duct (31). Endothelin has also been reported to activate phospholipase $A_{2}$ in several tissues, leading to the release of arachidonic acid which is then metabolized to prostaglandins, thromboxanes, or leukotrienes (3).

The participation of lipoxygenase metabolites in ET-induced natriuresis and diuresis was previously described in vivo by Perico et al. (5); however, they did not examine if cyclooxygenase activity was also essential to this process. Perico et al. (5) also reported that the effects of endothelin could be blocked by a leukotriene $\mathrm{D}_{4}$ receptor antagonist. We found that leukotriene $D_{4}$ 's do not participate in the inhibitory effect induced by ET-1, but that inhibition of the production of leukotrienes by blockade of lipoxygenase activity blocked the ET-1-induced inhibition of Jv.

Data from Stier et al. (32), using an isolated, perfused rat kidney, show that the effect of ET-3 on renal function were not modified by pretreatment with indomethacin indicating that prostaglandin were not involved. However, these results do not necessarily conflict with ours, since ET-3 has been shown to act via a different mechanism than ET-1 in vascular smooth muscle cells (33).

In proximal straight tubules pretreated with quinacrine we found that $10^{-9} \mathrm{M}$ ET-1 increased fluid absorption significantly indicating that inhibition is superimposed on stimulation. This stimulation was also observed in when $10^{-4} \mathrm{M}$ indomethacin was present or when both $10^{-5} \mathrm{M}$ indomethacin and ETI were present. These data seem to indicate that: $(a)$ both inhibitory cyclooxygenase and lipoxygenase products are produced when $10^{-9} \mathrm{M} \mathrm{ET}-1$ is present and that blocking only one pathway is insufficient to completely prevent the inhibitory effect; and 2) $10^{-4} \mathrm{M}$ indomethacin may inhibit lipoxygenase as well as cyclooxygenase activity.

The stimulation of $\mathrm{Jv}$ produced by ET- 1 in quinacrinetreated tubules was blocked by an inhibitor of PKC. In tubules pretreated with both quinacrine and staurosporine, $10^{-9} \mathrm{M}$ ET-1 had no effect on fluid absorption. Consequently we concluded that protein kinase $\mathrm{C}$ activates either phospholipase $\mathrm{A}_{2}$ and / or D. The ability of PKC to stimulate phospholipase activity and release arachidonic acid has been reported to occur in cortical collecting tubular cells treated with bradykinin (34).

From our results, we propose the following cascade for the bimodal effect of ET-1 on fluid absorption. First, the stimulatory effect produced by $10^{-13} \mathrm{M}$ ET- 1 is a result of activation of phospholipase $\mathrm{C}$ and consequent activation of PKC. Activation of PKC in this model increases fluid absorption. The inhibitory effect of ET-1 is a result of further activation of both phospholipase $C$ and PKC. This higher level of PKC activation causes stimulation of phospholipase $A_{2}$ and/or D. Activation of one or both phospholipases releases arachidonic acid. The arachidonic acid is metabolized into prostaglandin and leukotrienes, whose in turn inhibit fluid absorption.

\section{Acknowledgments}

This work was supported in part by grants from the National Institutes of Health (NIH) (HL-28982), National Kidney Foundation of Michigan, and the American Heart Association, National Center (91009430). Dr. Garvin was supported in part by a Research Career Development Award from the NIH (HL-02891) during this work.

\section{References}

1. Eiam-Ong, S., S. A. Hilden, A. J. King, C. A. Johns, and N. E. Madias. 1992. Endothelin-1 stimulates the $\mathrm{Na}^{+} / \mathrm{H}^{+}$and $\mathrm{Na}^{+} / \mathrm{HCO}_{3}^{-}$transporters in rabbit renal cortex. Kidney Int. 42:18-24.

2. Danthuluri, R. N., and T. A. Brock. 1990. Endothelin receptor-coupling mechanisms in vascular smooth muscle: a role for protein kinase C. J. Pharmacol. Exp. Ther. 254:393-399.

3. Sokolovky, M. 1992. Endothelins and sarafotoxins: physiological regulation, receptor subtypes and transmembrane signaling. Pharmacol. Ther. 54:129149.

4. Miller, W. L., M. M. Redfield, and J. C. Burnet. 1989. Integrated cardiac, renal, and endocrine actions of endothelin. J. Clin. Invest. 83:317-320.

5. Perico, N., R. P. Cornejo, A. Benigni, B. Malanchini, J. R. Landy, and G. Remuzzi. 1991. Endothelin induces diuresis and natriuresis in the rat by acting on the proximal cells through a mechanism mediated by lipoxygenase products. J. Am. Soc. Nephrol. 2(1):57-69.

6. Harris, P. J., J. Zhuo, F. A. O. Mendelsohn, and S. L. Skinner. 1991. Haemodynamics and renal tubular effects of low doses of endothelin in anaesthetized rats. J. Physiol. 433:25-39.

7. Garvin, J. L., and K. Sanders. 1991. Endothelin inhibits fluid and bicarbonate transport in part by reducing $\mathrm{Na}^{+} / \mathrm{K}^{+}$activity in the rat proximal straight tubule. J. Am. Soc. Nephrol. 2:976-982.

8. Guntupalli, J., R. Phelps, and T. D. DuBose. 1991. Effect(s) of endothelin1 (ET) on $\mathrm{Na}^{+}-\mathrm{Pi}$ cotransport and $\mathrm{Na}^{+} / \mathrm{H}^{+}$exchange in rat renal brush border membranes (BBM). J. Am. Soc. Nephrol. 2:402. (Abstr.)

9. Zeidel, M. L., H. R. Brady, B. C. Kone, S. R. Gullans, and B. M. Brenner 1989. Endothelin, a peptide inhibitor of $\mathrm{Na}^{+} / \mathrm{K}^{+}$ATPase in intact renal tubular epithelial cells. Am. J. Physiol. 257:C1101-C1107.

10. Burg, M. B., J. J. Grantham, M. Abramov, and J. Orloff. 1966. Preparation and study of fragments of single rabbit nephrons. Am. J. Physiol. 210:12931298.

11. Jones, T. R., R. Zamboni, M. Belley, E. Champion, L. Charette, A. W. Ford-Hutchinson, R. Frenette, J.-Y. Gauthier, S. Leger, P. Masson, C. S. McFarlane, H. Piechuta, J. Rokach, H. Williams, R. N. Young, R. N. DeHaven, and S. S. Pong. 1989. Pharmacology of L-660,711 (MK-571): a novel potent and selective leukotriene $\mathrm{D}_{4}$ receptor antagonist. Can. J. Physiol. Pharmacol. 67:1728. 
12. Garvin, J. L., M. B. Burg, and M. A. Knepper. 1985. Ammonium replaces potassium in supporting sodium transport by the $\mathrm{Na}^{+} / \mathrm{K}^{+}$ATPase of renal proximal straight tubules. Am. J. Physiol. 249:F785-F788.

13. Simonson, M. S., S. Wann, P. Mene, G. R. Dubyak, M. Kester, Y. Nakazato, J. R. Sedor, and M. J. Dunn. 1989. Endothelin stimulates phospholipase C, $\mathrm{Na}^{+} / \mathrm{H}^{+}$exchange, c- fos expression, and mitogenesis in rat messangial cells. $J$. Clin. Invest. 83:708-712.

14. Horie, S., O. Moe, Y. Yamaji, A. Cano, R. T. Miller, and R. J. Alpern. 1992. Role of protein kinase $\mathrm{C}$ and transcription factor AP-1 in the acid-induced increase in $\mathrm{Na}^{+} / \mathrm{H}^{+}$antiporter activity. Proc. Natl. Acad. Sci. USA. 89:52365240 .

15. Borgese, F., C. Sardet, M. Cappadoro, J. Pouyssegur, and R. Motais. 1992. Cloning and expression of cAMP-activated $\mathrm{Na}^{+} / \mathrm{H}^{+}$exchanger: Evidence that the cytoplasmic domain mediates hormonal regulation. Proc. Natl. Acad. Sci. USA. 89:6765-6769.

16. Liu, F.-Y., and M. G. Cogan. 1990. Role of protein kinase C in proximal bicarbonate absorption and angiotensin signaling. Am. J. Physiol. 258:F927F933.

17. Wijkander, J., and R. Sundler. 1992. Regulation of arachidonate-mobilizing phospholipase $\mathrm{A} 2$ by phosphorylation via protein kinase $\mathrm{C}$ in macrophages. FEBS (Fed. Eur. Biochem. Soc.) Lett. 311:299-301.

18. Kinoshita, Y., J. C. Romero, and F. G. Knox. 1989. Effect of renal interstitial infusion of arachidonic acid on proximal sodium reabsorption. $\mathrm{Am}$. J. Physiol. 257:F237-F242.

19. Yanagisawa, M., H. Kurihari, S., Kimusura, Y. Tomabe, M. Kobayashi, Y. Mitsui, K. Goto, and T. Masaki. 1988. A novel potent vasoconstrictor peptide produced by vascular endothelial cells. Nature (Lond.). 332:411-415.

20. Romero, M. F., U. Hopfer, Z. T. Madhun, W. Zhou, and J. G. Douglas. 1991. Angiotensin II actions in the rabbit proximal tubule. Renal Physiol. Bio chem. 14:199-207.

21. Olsen, M. E., J. E. Hall, J. P. Montani, A. C. Guyton, H. G. Langford, and J. E. Cornell. 1985. Mechanisms of angiotensin II natriuresis and antinatriuresis. Am. J. Physiol. 249:F299-F305.

22. Dymshitz, J., M. Laudon, and N. Ben-Jonathan. 1992. Endothelin-induced biphasic response of lactotrophs cultured under different conditions. Neuroendocrinology. 55:724-729.
23. Berne, R. M., and M. N. Levy. 1993. Physiology. Mosby Year Book. C. V. Mosby Co., St. Louis, MO. 1071 pp.

24. Yamaguchi, T., M. Fukase, M. Arao, T. Sugimoto, and K. Chihara. 1992. Endothelin-1 hydrolysis by rat kidney membranes. FEBS (Fed. Eur. Biochem. Soc.) Lett. 309:303-306.

25. Vijayaraghavan, J., A. G. Scicli, O. Carretero, C. Slaughter, C. Moomaw, and L. B. Hersh. 1990. The hydrolysis of endothelins by neutral endopeptidase 24.11 (enkephalinase). J. Biol. Chem. 265:14 150-14 155.

26. Terada, Y., K. Tomita, H. Nonoguchi, and F. Marumo. 1992. Different localization of two types of endothelin receptor mRNA in microdissected rat nephron segments using reverse transcription and polymerase chain reaction assay. J. Clin. Invest. 90:107-112.

27. Takemoto, F., S. Uchida, E. Ogata, and K. Kurokawa. 1993. Endothelin-1 and endothelin-3 binding to rat nephrons. Am. J. Physiol. 264:F827-F832.

28. Liu, Y., B. Geisguhler, and A. W. Jones. 1992. Activation of multiple mechanisms including phospholipase $\mathrm{D}$ by endothelin-1 in rat aorta. Am. J. Physiol. 262:C941-C949.

29. Bertorello, A., and A. Aperia. $1988 . \mathrm{Na}^{+} / \mathrm{K}^{+} \mathrm{ATPase}$ is an effector protein for protein kinase $\mathrm{C}$ in renal proximal tubule cells. Am. J. Physiol. 256 F9-F14.

30. Cohen-Luria, R., G. Rimon, and A. Moran. 1993. PGE2 inhibits $\mathrm{Na}^{+} / \mathrm{K}^{+}$ ATPase activity and ouabain binding in MDCK cells. Am. J. Physiol. 264: F61-F65.

31. Hébert, R. L., H. R. Jacobson, and M. D. Breyer. 1991. Prostaglandin E2 inhibits sodium transport in rabbit cortical collecting duct by increasing intracellular calcium. J. Clin. Invest. 87:1992-1998.

32. Stier, C. T., Jr., C. P. Quilley, and J. C. McGiff. 1992. Endothelin-3 effects on renal function and prostanoids release in the rat isolated kidney. J. Pharmacol. Exp. Ther. 262:252-256.

33. Little, P. J., C. B. Neylon, V. A. Tkachuk, and A. Bobik. 1992. Endothelin- 1 and endothelin-3 stimulate calcium mobilization by different mechanisms in vascular smooth muscle. Biochem. Biophys. Res. Commun. 183:694-700.

34. Dixon, B. S., R. Breckon, J. Fortune, E. Sutherland, F. R. Simon, and R. J. Anderson. 1989. Bradykinin activates protein kinase $\mathrm{C}$ in cultured cortical collecting tubular cells. Am. J. Physiol. 26:F808-F817. 